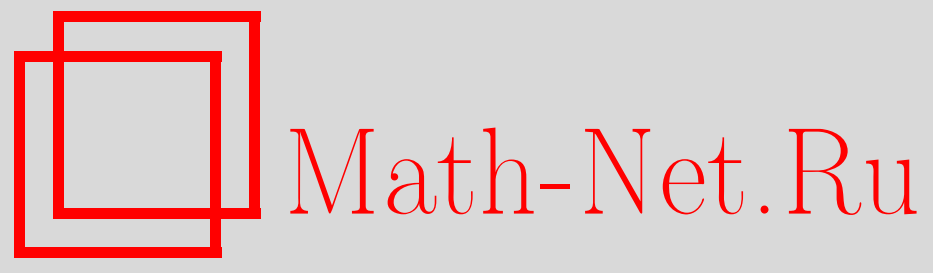

E. V. Murashkin, Yu. N. Radayev, O микрополярной 3D-теории растущих тел, Вестн. Сам. гос. техн. ун-та. Сер. Физ.-мат. науки, 2020, номер 3, 424444

DOI: https://doi.org/10.14498/vsgtu1792

Использование Общероссийского математического портала MathNet.Ru подразумевает, что вы прочитали и согласны с пользовательским соглашением

http: //www.mathnet.ru/rus/agreement

Параметры загрузки:

IP : 54.174 .149 .18

26 апреля 2023 г., 16:30:14

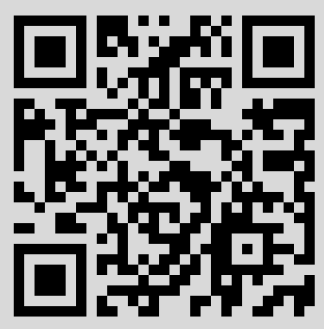




\title{
Mechanics of Solids
}

\author{
MSC: 74A20, 74A60
}

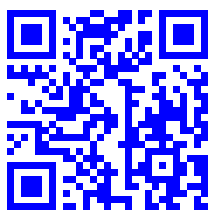

\section{On a micropolar theory of growing solids}

\author{
(C) E. V. Murashkin, Yu. N. Radayev
}

A. Ishlinsky Institite for Problems in Mechanics, Russian Academy of Sciences, 101, pr. Vernadskogo, Moscow, 119526, Russian Federation.

\begin{abstract}
The present paper is devoted to the problem of boundary conditions formulation in the growing micropolar solid mechanics. The static equations of the micropolar continuum in terms of relative tensors (pseudotensors) are derived due to virtual work principle for a solid of constant staff. The constitutive quadratic form of the elastic potential (treated as an absolute scalar) for a linear hemitropic micropolar solid is presented and discussed. The constitutive equations for symmetric and antisymmetric parts of force and couple stress tensors are given. The final forms of the static equations for the hemitropic micropolar continuum in terms of displacements and microrotations rates are obtained including the case of growing processes. A transformation of the equilibrium equations is proposed to obtain boundary conditions on the propagating growing surface in terms of relative tensors in the form of differential constraints. Those are valid for a wide range of materials and metamaterials. The algebra of rational relative invariants is intensively used for deriving the constitutive relations on the growing surface. Systems of joint algebraic rational relative invariants for force, couple stress tensors and also unit normal and tangent vectors to propagating growing surface are obtained, including systems of invariants sensitive to mirror reflections and 3D-space inversions.
\end{abstract}

Keywords: micropolar hemitropic continuum, microrotation, pseudoscalar, relative tensor, 3D printing, propagating growing surface, stress, constitutive equation, rational relative invariant, differential constraint, complete system.

\section{Research Article}

○ ()(-) The content is published under the terms of the Creative Commons Attribution 4.0 International License (http://creativecommons.org/licenses/by/4.0/)

Please cite this article in press as:

M u r ashkin E. V., R a d a y ev Yu. N. On a micropolar theory of growing solids, Vestn. Samar. Gos. Tekhn. Univ., Ser. Fiz.-Mat. Nauki [J. Samara State Tech. Univ., Ser. Phys. Math. Sci.], 2020, vol. 24, no. 3, pp. 424-444. https://doi.org/10.14498/vsgtu1792.

\section{Authors' Details:}

Evgenii V. Murashkin (10) https://orcid.org/0000-0002-3267-4742

Cand. Phys. \& Math. Sci., PhD, MD; Senior Researcher; Lab. of Modeling in Solid Mechanics; e-mail: evmurashkin@google.com

Yuri N. Radayev (1) https://orcid.org/0000-0002-0866-2151

D.Sc. (Phys. \& Math. Sci.), Ph.D., M.Sc., Professor; Leading Researcher; Lab. of Modeling in Solid Mechanics; e-mail:radayev@ipmnet.ru, y.radayev@gmail.com 
Received: $15^{\text {th }}$ June, $2020 /$ Revised: $17^{\text {th }}$ August, $2020 /$

Accepted: $14^{\text {th }}$ September, $2020 /$ First online: 30 ${ }^{\text {th }}$ September, 2020

\section{Introduction}

Modern methods of design and manufacture of products and complex shape structures are based on various technological processes of material processing (lamination, photopolymerization, stereolithography, winding, surfacing, freezing, ablation, segmentation, frontal and layer-by-layer curing) [1,2]. These manufacturing processes of additive technologies are associated with the products synthesis by sequentially adding material to the surface of an arbitrary (often abnormal) shape. It should be then noted that considered growth processes do not include the processes of the so-called volumetric growth [3-11]: the formation of a solid component in the process of a chemical reaction, the growth of biological tissues [6], bones [8,9], the natural formations of fruits [12]. At the same time, the procedure for choosing adequate boundary conditions on a propagating growing surface is an actual fundamental problem of modern continuum mechanics and applied mathematics. The boundary conditions play the an important role for the mathematical models of the growing solids. In addition, 3D materials used in additive manufacturing, as well as final products, have microstructural features and mechanical properties that are best described by asymmetric theories of continuum mechanics. Consequently, for the development of mathematical models of such technological processes for processing 3D materials and manufacturing 3D products, it is necessary to use the mechanics of growing solids (MGS) and the formalism of nonequilibrium thermodynamics in combination with the approaches of asymmetric theories.

The relative tensors is naturally arising in the mathematical models of micropolar material. In particular, these are: microrotation vector, wryness tensor, couple stress vector and tensor, microinertia, body couples. A literary search shows that the application of relative tensors in the theories of continuum mechanics is not wide spread, despite of the in-depth mathematical studies (algebra, theory of invariants and differentiation of relative tensors) [13-22]. The equations of the micropolar theory in terms of relative tensors or pseudotensors allows a deep insight of the physical and geometric nature of studied physical fields.

A solution of applied problem of growing solids mechanics is sometimes a sophisticated and time-consuming procedure [2,23-29]. A substantial feature of the boundary value problems statements in the MGS frameworks is the boundary conditions formulation on the interface between the source material and the added part [30-32].

The paper is arranged as follows. The first section of the paper is devoted to a formulation of the virtual work principle for a micropolar solid of constant staff. Differential constraints are taking into consideration by means of Lagrange multipliers rule. These multipliers are the reactions of the imposed kinematic constraints. The weights of the fundamental relative tensors are estimated and collected in table 1. 
In Sec. 2, the static equations of the micropolar coninuum in terms of relative tensors are derived. The final form of static equations in an arbitrary curvilinear coordinate system is obtained. The weights of relative tensors of micropolar elasticity are verified and given in table 2.

Sec. 3 of the paper is devoted to the constitutive form of the elastic potential (treated as an absolute scalar) for the hemitropic micropolar continuum. The weights of the micropolar hemitropic constitutive scalars are determined and then shown by table 3 . The static equations are obtained for displacements and microrotations for a semi-istropic (hemitropic) continuum of constant staff and generalized for a growing solid.

Then, in Sec. 4, the boundary conditions on the propagating growing surface are obtained by transforming the equilibrium equations of the micropolar continuum from the Sec. 2 of the paper. Boundary conditions are derived in the form of differential constraints for force and couple stress tensors.

In Sec. 5, systems of joint algebraic rational relative invariants of force stress tensor, couple stress tensor and the unit normal and tangent vectors to the propagating growing surface are presented in tables 4-6. The system of joint algebraic relative invariants insensitive to a coordinate frame rotation around the unit normal vector to the propagating growing surface is proposed and discussed.

The Sec. 6 deals with a system of invariants sensitive to mirror reflections and 3D-space inversions of local coordinate frame related to a propagating growing surface.

The final section contains concluding remarks and discussion of the paper.

\section{Variational principle for a micropolar continuum of constant staff}

Relative tensors naturally arise in the mechanics of elastic micropolar media. Throughout the paper in square brackets above the root symbol we will indicate the relative tensor weight. Hereafter, we will not denote zero weight of the relative tensor. Note that, the discussions and considerations in Secs. 1-3 are provided in the frameworks of virtual displacements principle formulated for a constant staff solid in Eulerian coordinate net. The form of static equations is held in case of micropolar growing solids. Following this way a derivation of static equations can by realized for non-growing solids and then generalized on a case of growing solids.

Virtual work due to force factors on virtual displacements $\delta u_{k}$ and microro$[+1]$

tations $\delta \phi^{i}$, can be furnished as an absolute scalar in following form [33]:

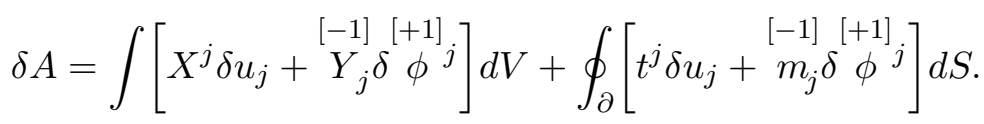

Hereafter, we will use invariant volume element $d V$ and invariant surface element $d S$ of the zero weight.

Small "rigid" displacement and "rigid" rotation close to the equilibrium state are equivalent the following differential constraints

$$
\nabla_{(i} \delta u_{k)}=0
$$




$$
\begin{aligned}
& \delta^{[+1]} \varphi^{i}=\delta^{[+1]} \phi^{i}-\frac{1}{2} \epsilon^{i k l} \nabla_{k} \delta u_{l}=0, \\
& \delta^{[+1]} \kappa_{i} \cdot s=\nabla_{i} \delta^{[+1]} \phi^{s}=0 .
\end{aligned}
$$

Here $\epsilon^{i k l}$ are the fundamental permutation symbols. Note that the permutation symbols is a pseudotensor of weight +1 in contravariant case and have weight -1 in covariant case. Hereafter, we will not denote the weight of these pseudotensors.

In case of constraints (3), according to the principle of virtual displacements, such "rigid" motions can be performed without "cost" of work, i.e. virtual work is vanished:

$$
\delta A=0,
$$

The most important distinguishing feature in the variational equation (4) is the absence contributions of the work of "internal" force factors. In this case the principle of virtual displacements is derived in a very simple analytical form.

Thus, the principle of virtual displacements is a variational equation (4), with differential constraints imposed on variations (1)-(3). Therefore, further discussions will be based on the Lagrange multiplier rule [33]. Variational equation (4) we

\begin{tabular}{|c|c|c|c|}
\hline Standard terminology & Root notation & Weight & $\begin{array}{l}\text { Transformation } \\
\text { to absolute tensor }\end{array}$ \\
\hline determinant defined by Jacobian & $\Delta=\operatorname{det}\left(\overline{\partial_{j}} x^{i}\right)$ & - & $g \Delta^{2}=\bar{g}$ \\
\hline contravariant permutation symbol & $\epsilon^{i j k}$ & +1 & $e^{i j k}=\frac{1}{e}^{[+1]} \epsilon^{i j k}$ \\
\hline covariant permutation symbol & $\epsilon_{i j k}$ & -1 & $e_{i j k}=e \epsilon_{i j k}$ \\
\hline metric tensor & $g_{i j}$ & 0 & \\
\hline fundamental tensor & $g^{i j}$ & 0 & \\
\hline metric tensor determinant & $g$ & +2 & $\stackrel{[+2]}{g}=e^{2}$ \\
\hline metric tensor determinant sign & $\operatorname{sgn} g$ & 0 & \\
\hline fundamental tensor determinant & $g^{-1}$ & -2 & ${ }^{[-2]}-1=e^{-2}$ \\
\hline fundamental orienting scalar in $3 \mathrm{D}$ & $e$ & +1 & $\stackrel{[+1]}{e}=e$ \\
\hline $\begin{array}{l}\text { inverse fundamental } \\
\text { orienting scalar in } 3 \mathrm{D}\end{array}$ & $\frac{1}{e}$ & -1 & $e^{[-1]}-1=\frac{1}{e}$ \\
\hline invariant volume element & $d V$ & 0 & \\
\hline natural volume element & $d \tau$ & -1 & $d V=e^{[-1]} d \tau$ \\
\hline Hamilton nabla & $\nabla_{i}$ & 0 & \\
\hline
\end{tabular}

Table 1

Fundamental relative tensors of continuum mechanics 
will replace with a new one, with Lagrange multipliers by eliminating constraints (1)-(3). For this purpose, the multipliers of different types are introduced:

(i) $\sigma^{(i k)}$ is first (symmetric) absolute tensor multiplier;

$[-1]$

(ii) $\tau_{j}$ is second pseudovector multiplier; $[-1]$

(iii) $\mu_{. k}^{i \cdot}$ is third pseudotensor multiplier.

As a result, instead of the variational equation (4) one can obtain a new variational equation with independent variations $\delta u_{k}$ and $\delta \phi^{i}$ :

$$
\begin{aligned}
& \int\left[X^{j} \delta u_{j}+{ }^{[-1]} Y_{j} \delta \phi^{j}-\sigma^{(i k)} \nabla_{(i} \delta u_{k)}-2^{[-1]} \tau_{i}^{\left[{ }^{[+1]}\right.}{ }^{i}{ }^{i}-\frac{1}{2} \epsilon^{i k l} \nabla_{k} \delta u_{l}\right)- \\
& \left.-{ }^{[-1]} \mu_{\cdot k}^{i \cdot} \nabla_{i} \delta^{[+1]} \phi^{k}\right] d V+\oint_{\partial}\left[t^{j} \delta u_{j}+m_{j}^{[-1]} \delta^{[+1]} \phi^{j}\right] d S=0 .
\end{aligned}
$$

Introducing following notation

$$
t^{[i k]}=-\epsilon^{i k j}{ }^{[-1]}
$$

the equation (5) can be transformed into

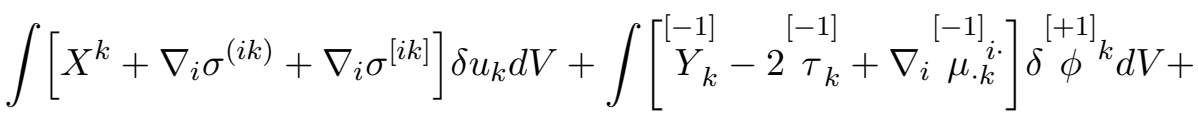

$$
\begin{aligned}
& +\oint_{\partial}\left[t^{k}-n_{i}\left(\sigma^{(i k)}+\sigma^{[i k]}\right)\right] \delta u_{k} d S+\oint_{\partial}\left[\begin{array}{c}
{[-1]} \\
m_{k}-n_{i} \mu_{\cdot k}{ }^{i \cdot-1]}
\end{array}\right] \delta^{[+1]} \phi^{k} d S=0 \text {, }
\end{aligned}
$$

where $n_{i}$ are the unit vector components of the external normal to the outer surface $\partial$ of the solid.

\section{Static equations of growing micropolar continuum}

The differential equations of equilibrium are derived from the equation (6) by considering those in Eulerian (spatial) coordinate net due to the arbitrariness of the variations $\delta u_{k}$ and $\delta \phi^{[+1]}$. These equations read

$$
\begin{aligned}
& \nabla_{i} \sigma^{i k}=-X^{k} \\
& \nabla_{i} \mu_{\cdot k}^{i-1]}-2 \tau_{k}=-Y_{k}^{[-1]},
\end{aligned}
$$

where the asymmetric Lagrange multiplier is introduced according to the equation

$$
\sigma^{i k}=\sigma^{(i k)}+\sigma^{[i k]} .
$$

Note that variations $\delta u_{k}$ and $\delta^{[+1]} \phi^{i}$ remain their sense for growing solids while considering in Eulerian coordinates. The formulation of variational principle for varied domain is discussed in [29]. 
Table 2

Relative tensors of the micropolar elasticity

\begin{tabular}{|c|c|c|c|}
\hline Standard terminology & Root notation & Weight & $\begin{array}{l}\text { Transformation } \\
\text { to absolute tensor }\end{array}$ \\
\hline displacements vector & $u^{k}$ & 0 & \\
\hline asymmetric strain tensor & $\epsilon_{i j}$ & 0 & \\
\hline small strain tensor & $\epsilon_{(i j)}=\varepsilon_{i j}$ & 0 & \\
\hline force traction vector & $t^{k}=n_{i} \sigma^{i k}$ & 0 & \\
\hline force stress tensor & $\sigma^{i k}$ & 0 & \\
\hline body forces & $X^{k}$ & 0 & \\
\hline elastic potential & $\mathscr{U}$ & 0 & \\
\hline mass density & $\rho$ & 0 & \\
\hline couple traction vector & $m_{k}=n_{i} \mu_{\cdot k}^{i}$ & -1 & $m_{k}=e^{[-1]} m_{k}$ \\
\hline couple stress tensor & $\mu_{\cdot k}^{i}$ & -1 & $\mu_{\cdot k}^{i \cdot}=e^{[-1]} \mu_{\cdot k}^{i \cdot}$ \\
\hline associated couple stress vector & $\mu^{i}$ & 0 & \\
\hline associated couple stress vector & $\tau_{k}$ & -1 & $\tau_{k}=e^{[-1]} \tau_{k}$ \\
\hline body couples & $Y_{k}$ & -1 & $Y_{k}=e^{[-1]} Y_{k}$ \\
\hline microinertia & $\Im$ & -2 & $\Im=e^{2} \stackrel{[-2]}{\Im}$ \\
\hline microrotation tensor & $\Omega_{i k}$ & 0 & \\
\hline microrotation vector & $\phi^{i}$ & +1 & $\phi^{i}=\frac{1}{e}^{[+1]} \phi^{i}$ \\
\hline wryness tensor & $\kappa_{i}^{\cdot s}$ & +1 & $\kappa_{i \cdot}^{\cdot s}=\frac{1}{e} \kappa_{i \cdot}^{[+1]} \cdot s$ \\
\hline associated wryness vector & $\kappa_{i}$ & 0 & \\
\hline
\end{tabular}

The following equations are additionally derived from variational equation (6) on the boundary surface

$$
n_{i} \sigma^{i k}=t^{k}, \quad n_{i} \mu_{\cdot k}^{[-1]}=\stackrel{[-1]}{m_{k}} .
$$

The above results allow us to conclude that the Lagrange multipliers $\sigma^{(j k)}$, $[-1][-1]$.

$\tau_{j}, \mu_{\cdot k}^{i \cdot}$ represent the reactions of the imposed constraints, respectively, by the constraints characterising the "rigid" displacements and "rigid" rotations

$$
\epsilon_{(j k)}=0, \quad \varphi^{[+1]}=0, \quad \stackrel{[+1]}{\kappa_{i} \cdot k}=0 .
$$


It is also clear that in the physical sense the second-rank tensors $\sigma^{j k}$ and $\mu_{. k}^{i}{ }^{i}$ are force stress tensor and couple stress tensor respectively. It is obvious that the force stress tensor $\sigma^{i k}$ is an absolute second-rank tensor, and the couple stress $[-1]$

tensor $\mu_{. k}^{i \cdot}$ is a relative tensor of weight -1 .

In the further considerations, the following antisymmetric tensors and their associated vectors will be used

$$
{ }^{[-1]} \tau_{j}=\frac{1}{2} \epsilon_{j i k} t^{[i k]}, \quad+\mu^{i}=\frac{1}{2} \epsilon^{i k s^{[-1]}} \mu_{[k s]} .
$$

Let us derived the covariant derivatives in accordance with the rules of covariant differentiation of relative tensors $[13,14,18,22]$. Thus, the static equations (7) are furnished by

$$
\begin{aligned}
& \partial_{i} \sigma^{i k}+\sigma^{s k} \Gamma_{s i}^{i}+\sigma^{i s} \Gamma_{s i}^{k}=-X^{k},
\end{aligned}
$$

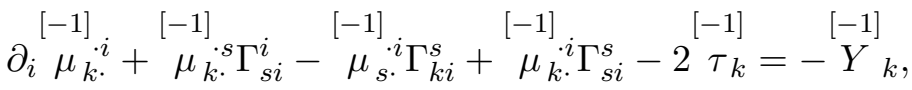

where $\partial_{i}$ denotes a partial derivative on the spatial coordinate $x^{i}$.

To formulate boundary value problems in the frameworks of the theory of asymmetric elasticity, it is necessary to specify the forces $t^{k}$ and the couples $m_{k}$ acting on the outer surface of the solids.

The final form of the equations (9), (10) in combination with the boundary conditions (8) give a general statement of the boundary value problem in the micropolar elasticity frameworks in an arbitrary curvilinear coordinate net.

\section{Hemitropic micropolar media}

Let's apply the formalism of relative tensors $[17-19,22]$ to the model of the linear hemitropic micropolar continuum of constant staff. The static equations derived for a constant staff solid by the virtual work principle with special constitutive form of elastic potential in terms of rates will be held true for the growing solids. For a micropolar continuum with one director, the elastic potential ${ }^{1} \mathscr{U}$ with appropriate arguments can be taken in the form $[33,37,38]$

$$
\mathscr{U}=\mathscr{U}\left(\epsilon_{(i j)}, \stackrel{[+1]}{\kappa}{ }^{(i j)}, \stackrel{[+1]}{\varphi^{i}}, \kappa_{i}\right),
$$

where $\epsilon_{(i j)}$ is small strain tensor (absolute tensor), ${ }^{[+1]}{ }^{(i j)}$ is the symmetric part of the wryness tensor (the relative tensor of weight +1$), \varphi^{[+1]}$ is vector of relative microrotation (relative vector of weight +1 ), $\kappa_{i}$ is the associated wryness vector (absolute vector).

First variation of $\mathscr{U}$ is obtained according to equation

$$
\delta \mathscr{U}=\sigma^{(i j)} \delta \epsilon_{(i j)}+{ }^{[-1]} \mu_{(i j)} \delta^{[+1]} \kappa^{(i j)}+2^{[-1]} \tau_{i}^{[+1]} \varphi^{i}+2 \mu^{i} \delta \kappa_{i} .
$$

\footnotetext{
${ }^{1}$ The elastic potential $\mathscr{U}$ is an absolute scalar of the zero weight.
} 
In the case of a continuum exhibiting semi-isotropic (hemitropic) properties, i.e. one are insensible for a rotation and sensible with respect to mirror reflections and $3 \mathrm{D}$-space inversion, potential $\mathscr{U}$ can be presented in the quadratic form by

$$
\begin{aligned}
& \mathscr{U}=G \nu(1-2 \nu)^{-1} g^{i s} g^{l m} \epsilon_{(i s)} \epsilon_{(l m)}+G \stackrel{[-1][-1]}{L} L c_{3} g_{i s} g_{l m}{ }^{[+1]}{ }^{(i s)}{ }^{[+1]}{ }^{(l m)}+ \\
& +G g^{i s} g^{l m} \epsilon_{(i l)} \epsilon_{(s m)}+G \stackrel{[-1][-1]}{L} L g_{i s} g_{l m}{ }^{[+1]} \kappa^{(i l)}{ }^{[+1]} \kappa(s m)+2 G^{[-2]} c_{1} g_{i s} \delta^{[+1]} \varphi^{i} \delta^{[+1]} \varphi^{s}+ \\
& +G \stackrel{[-1][-1][+2]}{L} \stackrel{L}{L} c_{2} g^{i s} \kappa_{i} \kappa_{s}+G^{[-1]} c_{4} g^{i s} g_{l m} \epsilon_{(i s)} \kappa^{[+1]}{ }^{(l m)}+ \\
& +G^{[-1]} c_{5} \epsilon_{(i s)} \kappa^{[+1]}(i s)+G \stackrel{[-1]}{L} c_{6} \kappa_{i} \delta^{[+1]} \varphi^{i},
\end{aligned}
$$

where $G$ is the shear modulus of elasticity; $\nu$ is the Poisson ratio; $\stackrel{[-1]}{L}$ is the char$[-2][+2]$

acteristic length of micropolar theory; $c_{1}, c_{2}, c_{3}, c_{4}, c_{5}, c_{6}$ are the dimensionless constitutive pseudoscalars. The weights of the micropolar hemitropic constitutive scalars are shown in table 3.

Then the constitutive equations of a hemitropic micropolar growing medium can be furnished by in the form

$$
\begin{aligned}
& \left.\sigma^{(i s)}=2 G\left(\nu(1-2 \nu)^{-1} g^{i s} g^{l m}+g^{i l} g^{s m}\right) \epsilon_{(l m)}+G^{[-1]} L^{\left(c_{4} g^{i s} g_{l m} \kappa^{[+1]}(l m)+c_{5} \kappa^{[+1]}(i s)\right.}\right), \\
& \left.\stackrel{[-1]}{\mu_{(i s)}}=2 G^{[-1][-1]} L\left(c_{3} g_{i s} g_{l m}+g_{i l} g_{s m}\right)^{[+1]} \kappa^{(l m)}+G^{[-1]} L^{\left(c_{4}\right.} g_{i s} g^{l m} \epsilon_{(l m)}+c_{5} \epsilon_{(i s)}\right), \\
& \stackrel{[-1]}{\tau_{i}}=2 G^{[-2]} c_{1} g_{i s}{ }^{[+1]} \varphi^{s}+\frac{1}{2} G \stackrel{[-1]}{L} c_{6} \kappa_{i}, \\
& \mu^{i}=G \stackrel{[-1][-1][+2]}{L} \stackrel{c_{2}}{L} c_{2} g^{i s} \kappa_{s}+\frac{1}{2} G \stackrel{[-1]}{L} c_{6}{ }^{[+1]}{ }^{i} \text {. }
\end{aligned}
$$

Consider the fundamental orienting scalar powers ${ }^{2} e^{m}$ and take account of equation

$$
\nabla_{i} e^{m}=0 \quad(m= \pm 1, \pm 2, \cdots) .
$$

The equation (11) can be easily proved. Note, that a tensor equation involving relative tensors when true in one coordinate system is valid in all coordinate systems [18]. Let's consider the equation (11) in a right-handed Cartesian coordinate net. Actually, in this case a covariant derivative in (11) is a partial one. Then, in a right-handed Cartesian coordinate net $e=1$. Thus, the equation (11) is trivially fulfilled which proves it actuality in any curvilinear coordinate net.

\footnotetext{
${ }^{2}$ Orienting pseudoscalar of weight +1 in a three-dimensional space is determined by the equation

$$
e={ }^{[+1]}=\underset{1}{\boldsymbol{\imath}} \cdot(\underset{2}{\boldsymbol{\imath}} \times \underset{3}{\boldsymbol{\imath}}),
$$

$\underset{k}{\boldsymbol{\imath}}(k=1,2,3)$ are the local coordinate frame base vectors. This definition holds true only in three-dimensional space. For the case of multidimensions see $[39,40]$.
} 
Table 3

The weights of the micropolar hemitropic constitutive scalars

\begin{tabular}{|c|c|c|c|}
\hline Standard terminology & Root notation & Weight & $\begin{array}{l}\text { Transformation } \\
\text { to absolute tensor }\end{array}$ \\
\hline shear modulus of elasticity & $G$ & 0 & \\
\hline the Poisson ratio & $\nu$ & 0 & \\
\hline $\begin{array}{l}\text { characteristic length } \\
\text { of the micropolar theory }\end{array}$ & $L$ & -1 & $L=e^{[-1]}$ \\
\hline $\begin{array}{l}\text { dimensionless } \\
\text { micropolar modulus i }\end{array}$ & $c_{1}$ & -2 & $c_{1}=e^{2^{[-2]}} c_{1}$ \\
\hline $\begin{array}{l}\text { dimensionless } \\
\text { micropolar modulus ii }\end{array}$ & $c_{2}$ & +2 & $c_{2}=\frac{1}{e^{2}}{ }^{[+2]} c_{2}$ \\
\hline $\begin{array}{l}\text { dimensionless } \\
\text { micropolar modulus iii }\end{array}$ & $c_{3}$ & 0 & \\
\hline $\begin{array}{l}\text { dimensionless } \\
\text { micropolar modulus iv }\end{array}$ & $c_{4}$ & 0 & \\
\hline $\begin{array}{l}\text { dimensionless } \\
\text { micropolar modulus } \mathrm{v}\end{array}$ & $c_{5}$ & 0 & \\
\hline $\begin{array}{l}\text { dimensionless } \\
\text { micropolar modulus vi }\end{array}$ & $c_{6}$ & 0 & \\
\hline constitutive pseudoscalar i & $\underset{1}{A}$ & 0 & \\
\hline constitutive pseudoscalar ii & $\underset{2}{A}$ & -2 & $\underset{2}{A}=e^{2} \underset{2}{A}$ \\
\hline constitutive pseudoscalar iii & $\underset{3}{A}$ & 0 & \\
\hline constitutive pseudoscalar iv & $\underset{4}{A}$ & -2 & $\underset{4}{A}=e^{2^{[-2]}} \underset{4}{A}$ \\
\hline constitutive pseudoscalar $\mathrm{v}$ & $\begin{array}{c}A \\
5\end{array}$ & -2 & $\underset{5}{A}=e^{2} \underset{5}{A}$ \\
\hline constitutive pseudoscalar vi & $\underset{6}{A}$ & 0 & \\
\hline constitutive pseudoscalar vii & $\begin{array}{l}A \\
7\end{array}$ & -1 & $\underset{7}{A}=e \underset{7}{A}$ \\
\hline constitutive pseudoscalar viii & $\underset{8}{A}$ & -1 & $\underset{8}{A}=e \underset{8}{A}$ \\
\hline constitutive pseudoscalar ix & $\begin{array}{c}A \\
9\end{array}$ & -1 & $\underset{9}{A}=e \underset{9}{A}$ \\
\hline
\end{tabular}


Introducing the following notations

$$
c_{4}^{\prime}=c_{4}+\frac{1}{2} c_{5}+\frac{1}{4} c_{6}, \quad c_{5}^{\prime}=\frac{1}{2} c_{5}-\frac{1}{4} c_{6}, \quad c_{6}^{\prime}=-c_{6},
$$

and in view of equation (11) we derive the prefinal static equations for the hemitropic micropolar continuum in terms of displacements and microrotations

$$
\begin{aligned}
& G\left[\left(1+e^{2}{ }^{[-2]} c_{1}\right) \nabla^{s} \nabla_{s} u^{i}+\left(1-e^{2} c_{1}^{[-2]}+2 \nu(1-2 \nu)^{-1}\right) \nabla^{i} \nabla_{k} u^{k}+\right. \\
& \left.+2{ }^{[-2]} c_{1} \epsilon^{i k l} \nabla_{k}{ }^{[+1]} \phi_{l}+{ }^{[-1]} L c_{4}^{\prime} \nabla^{i} \nabla_{k}{ }^{[+1]}{ }^{k}+{ }^{[-1]}{ }^{[-} c_{5}^{\prime} \nabla^{k} \nabla_{k}{ }^{[+1]}{ }^{i}\right]=-X^{i}, \\
& G^{[-1][-1]} L{ }^{L}\left[\left(1+e^{-2} c_{2}^{[+2]}\right) \nabla^{s} \nabla_{s}{ }^{[+1]} \phi_{i}+\left(1-e^{-2^{[+2]}} c_{2}+2 c_{3}\right) \nabla_{i} \nabla_{k}{ }^{[+1]}{ }^{k}+\right. \\
& \left.+{ }^{[-1]}{ }^{-1} c_{4}^{\prime} \nabla_{i} \nabla^{k} u_{k}+{ }^{[-1]}{ }^{-1} c_{5}^{\prime} \nabla^{k} \nabla_{k} u_{i}+{ }^{[-1]}{ }^{-1} c_{6}^{\prime} \epsilon_{i s l} \nabla^{s}{ }^{[+1]} l\right]- \\
& -2 G^{[-2]} c_{1}\left(2^{[+1]} \phi_{i}-\epsilon_{i k l} g^{k s} \nabla_{s} u^{l}\right)=-{ }^{[-1]} Y_{i},
\end{aligned}
$$

where "+" corresponds to the right-handed coordinate net, and the sign "-_" corresponds to the left-handed one.

The static equations in mechanics of growing solids are often conveniently furnished by the rate equations. Thus, taking account of the independence of body forces and couples on time after simple transformations equations (12) read by

$$
\begin{aligned}
& G\left[\left(1+e^{2}{ }^{[-2]} c_{1}\right) \nabla^{s} \nabla_{s} v^{i}+\left(1-e^{2} c_{1}^{[-2]}+2 \nu(1-2 \nu)^{-1}\right) \nabla^{i} \nabla_{k} v^{k}+\right. \\
& \left.+2 c_{1} \epsilon^{i k l} \nabla_{k}{ }^{[+1]} \Omega_{l}+{ }^{[-1]} L c_{4}^{\prime} \nabla^{i} \nabla_{k}^{[+1]} \Omega^{k}+{ }^{[-1]} c_{5}^{\prime} \nabla^{k} \nabla_{k}^{[+1]} \Omega^{i}\right]=0, \\
& G^{[-1][-1]} L\left[\left(1+e^{-2} c_{2}^{[+2]}\right) \nabla^{s} \nabla_{s}^{[+1]} \Omega_{i}+\left(1-e^{-2^{[+2]}} c_{2}+2 c_{3}\right) \nabla_{i} \nabla_{k}^{[+1]} \Omega^{k}+\right. \\
& \left.+{ }^{[-1]}-1 c_{4}^{\prime} \nabla_{i} \nabla^{k} v_{k}+{ }^{[-1]}{ }^{-1} c_{5}^{\prime} \nabla^{k} \nabla_{k} v_{i}+L^{[-1]}{ }^{-1} c_{6}^{\prime} \epsilon_{i s l} \nabla^{s}{ }^{[+1]} l\right]- \\
& -2 G^{[-2]} c_{1}\left(2 \stackrel{[+1]}{\Omega_{i}}-\epsilon^{p q n} g_{i p} g_{k q} g_{l n} g^{k s} \nabla_{s} v^{l}\right)=0 \text {, }
\end{aligned}
$$

where $v^{k}$ are the velocities components, $\stackrel{[+1]}{\Omega_{k}}$ are the angular velocities of microrotations.

Note, that the rate form of static equations (13) furnishing in a Eulerian coordinate net hold true in a case of micropolar growing solid.

\section{Differential constraints on a micropolar growing surface}

The considerations in the section are provided by the transformation of the static equations obtaining in Sec. 2. The equation in Eulerian coordinates can be applied for describing behavior of growing solids. The similar method is indepth discussed for a Cartesian coordinate net in the book [32, pp. 288-292] 
by G. I. Bykovtsev. Here we use notation and terminology introducing in the studies [41-43], where the differential constraints for the force stress tensor are derived and discussed. Let's analytically define a propagating growing surface $\Sigma$ in three-dimensional space by the equation

$$
t=\underset{*}{\tau}\left(x^{i}\right)
$$

Then the unit normal vector $n_{i}$ on the propagating growing surface $\Sigma$ directed towards its propagation is related to the spatial gradient (14) by the equation

$$
n_{i}=c \partial_{i} \tau_{*}, \quad c=\left|\nabla_{*}^{\tau}\right|^{-1} \quad(t=\underset{*}{\tau}),
$$

where $c$ is the linear velocity of propagating growing surface in the normal direction $n_{k}$.

As previously shown (see for example, [41-43]), the transformation of equations of equilibrium (7) using a formula for the actual components of the force stress tensor $\sigma^{i j}$

$$
\begin{aligned}
& \sigma^{i j}=\int_{\substack{\tau+0 \\
*}}^{t}\left[\partial . \sigma^{i j}\left(x^{s}, t^{\prime}\right)\right] d t^{\prime}+\mathscr{S}^{j i}+\sigma_{*}^{i j}\left(x^{s}\right), \\
& \mathscr{S}^{i j}=\int_{\substack{\tau-0 \\
*}}^{\tau+0}\left[\partial . \sigma^{i j}\left(x^{s}, t^{\prime}\right)\right] d t^{\prime},
\end{aligned}
$$

allows us to derive the equation on the propagating growing surface in the form of the following differential constraints

$$
c\left[\nabla_{j} \sigma_{*}^{j i}\left(x^{s}\right)+\nabla_{j} \mathscr{S}^{j i}+\underset{*}{X^{i}}\left(x^{s}\right)\right]-n_{j} \partial . \sigma^{j i}\left(x^{s}, t\right)=0 \quad(t=\underset{*}{\tau}+0) .
$$

In equations (16)-(18) we use the notation adopted in [41-43]: $\mathscr{S}^{j i}$ is the stress jump related integral, $\sigma_{*}^{i j}\left(x^{s}\right)=\left.\sigma^{i j}\left(x^{s}, t\right)\right|_{t=\tau\left(x^{s}\right)-0}$ are the stress tensor components, respectively, at the moment $t=\tau_{*}\left(x^{s}\right)-0$ right before when the element is included in the main solid, $X_{*}^{i}\left(x^{s}\right)=\left.X^{i}\left(x^{s}, t\right)\right|_{t=\tau\left(x^{s}\right)+0}$. Moment $t=\tau_{*}\left(x^{s}\right)+0$ corresponds to the moment right after attaching the element to the growing surface.

Formulas for the components of the couple stress tensor, by analogy with the equations (16) can be assume in the following form

$$
\begin{aligned}
& \stackrel{[-1]}{\mu_{\cdot k}^{i \cdot}}=\int_{\tau+0}^{t}\left[\partial \cdot \mu_{\cdot k}^{[-1]}{ }_{i \cdot k}^{i \cdot}\left(x^{s}, t^{\prime}\right)\right] d t^{\prime}+\stackrel{[-1]}{\mathscr{M}_{\cdot k}^{i}}+\underset{*}{\mu_{\cdot k}^{i}}\left(x^{s}\right), \\
& \stackrel{[-1]}{\mathscr{M}}_{\cdot k}^{i \cdot}=\int_{\substack{\tau-0 \\
*}}^{\tau+0}\left[\partial \cdot \mu_{\cdot k}^{[-1]}{ }^{i \cdot}\left(x^{s}, t^{\prime}\right)\right] d t^{\prime}
\end{aligned}
$$

where $\stackrel{[-1]}{\mathscr{M}_{\cdot k}^{i \cdot}}$ is the couples jump related integral, $\underset{*}{\underset{*}{\mu} \cdot \overrightarrow{i \cdot k}}\left(x^{s}\right)=\left.\stackrel{[-1]}{\mu_{\cdot k}^{i}} \cdot\left(x^{s}, t\right)\right|_{t=\tau\left(x^{s}\right)-0}$ are the components of the couple stress tensor at time $t=\tau_{*}\left(x^{s}\right)-0$. 
After substitution of the actual couple stresses components (19) into equations of equilibrium (7) one can obtain

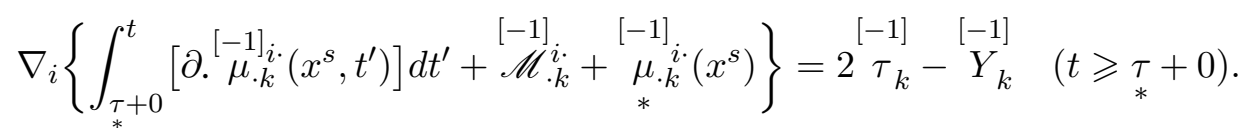

The next transformations of equation (20) is performed by derivative calculation according to the parametric integral differentiation rule. Note that the lower limit of integration depends on spatial coordinates $x^{s}$ which play a role of the parameters. Following with way one can derive

$$
\begin{aligned}
& \int_{*+0}^{t} \nabla_{i}\left[\partial \cdot{ }^{[-1]} \mu_{\cdot k}^{i \cdot}\left(x^{s}, t^{\prime}\right)\right] d t^{\prime}+\nabla_{i}^{[-1]} \mathscr{M}_{\cdot k}^{i \cdot}-\left(\nabla_{i} \tau_{*}\right)\left[\partial .^{[-1]} \mu_{\cdot k}^{i \cdot}\left(x^{s}, t\right)\right]_{t=\tau\left(x^{s}\right)+0}+ \\
& +\nabla_{i}^{[-1]} \underset{*}{\mu_{*}^{i \cdot}}\left(x^{s}\right)=2 \tau_{k}^{[-1]}-Y_{k}^{[-1]}(t \geqslant \underset{*}{\tau}+0) .
\end{aligned}
$$

Upon substituting the equation (15) in (21) we can write

$$
\begin{aligned}
& \int_{\tau_{*}+0}^{t} \nabla_{i}\left[\partial{ }^{[-1]} \mu_{\cdot k}^{i \cdot}\left(x^{s}, t^{\prime}\right)\right] d t^{\prime}+\nabla_{i} \stackrel{[-1]}{i \cdot}_{\cdot k}^{i \cdot}-\left[c^{-1} n_{i} \partial{ }^{[-1]} \mu_{\cdot k}^{i \cdot}\left(x^{s}, t\right)\right]_{t=\tau\left(x^{s}\right)+0}+ \\
& +\nabla_{i} \underset{*}{\mu_{*}^{[-1]}}{ }_{i \cdot}^{i \cdot}\left(x^{s}\right)=2 \tau_{k}^{[-1]}-{ }^{[-1]} Y_{k} \quad(t=\underset{*}{\tau}+0) .
\end{aligned}
$$

The following equation can be obtained by integrating (22) and taking account of (7), then reordering the covariant derivatives

$$
\begin{aligned}
& \nabla_{i} \stackrel{[-1]}{\mathscr{M}}_{\cdot k}^{i \cdot}-\left[c^{-1} n_{i} \partial .^{[-1]} \mu_{\cdot k}^{i \cdot}\left(x^{s}, t\right)\right]_{t=\tau\left(x^{s}\right)+0}+\nabla_{i}{ }_{*}^{[-1]_{\cdot k} \cdot}\left(x^{s}\right)+ \\
& +2 \tau_{k}^{[-1]}-{ }^{[-1]} Y_{k}-2 \underset{*}{\tau_{k}^{[-1]}}+\underset{*}{Y_{k}^{[-1]}}=2 \tau_{k}^{[-1]}-Y_{k}^{[-1]} Y_{*}(t=\underset{*}{\tau}+0),
\end{aligned}
$$

where $\underset{*}{Y_{k}}\left(x^{s}\right)=\left.\stackrel{[-1]}{Y_{k}}\left(x^{s}, t\right)\right|_{t=\tau\left(x^{s}\right)+0}, \quad \underset{*}{\tau_{k}}\left(x^{s}\right)=\stackrel{[-1]}{\left.\tau_{k}\left(x^{s}, t\right)\right|_{t=\tau}\left(x^{s}\right)+0}$.

Rearrangement of the terms in equation (23) leads to the final form of differential constraint on the propagating growing surface for the couple stress tensor

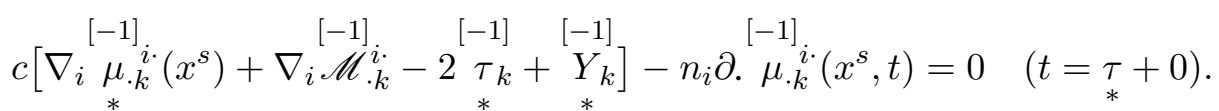

In the general case, the forces stresses $\sigma_{*}^{i j}$ and couples ones $\left.\underset{*}{\mu_{*}}\right]_{i}$ are to be expressed in terms of the actual stresses and couples on propagating growing surface by a tensor constitutive equations as follows

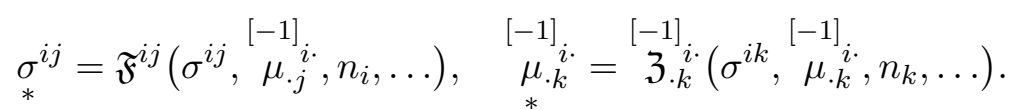


The functions $\mathfrak{F}_{i j}$ and $\stackrel{[-1]}{\mathfrak{Z}} . k_{.}^{i \cdot}$ can be defined by black box approach characterizing evaluation parameters in time interval $\underset{*}{\tau-0}-t \leqslant \tau_{*}+0$ right before attaching elements on a growing solid. In particular, the functions $\mathfrak{F}_{i j}$ and ${ }^{[-1]}{ }_{i}^{i} \cdot{ }^{\cdot}$ may depend on the microstructural directors and the thermophysical hidden variables associated with propagating growing surface. The functions $\mathfrak{F}_{i j}$ and $\stackrel{[-1]}{\mathfrak{Z}} . k_{k}^{i}$, in fact, should depend on combinations of arguments which are invariant under coordinate frame rotations around the unit normal vector $n_{k}$.

\section{System of joint algebraic relative invariants}

As we can see from the discussion in Sec. 4, the relative tensors associated with a growing solid and the propagating growing surface are the unit normal and tangent vectors, force and couples stress tensors. It is the tensor objects that define stress-strain state in micropolar material built up on the propagating growing surface. It is reasonable in further considerations to take account of $n_{i}$ unit normal vector that determines local geometry of the propagating growing surface and to introduce a local orthonormal coordinate frame base vectors involving the unit normal vector $n_{i}$ and two independent tangent vectors $\tau_{1}$ and $\underset{2}{\tau_{i}}$ in a tangent plane to the propagating growing surface.

Throughout the paper we deal with the second-rank tensors and vectors. The completeness problem of invariants system is in-depth studied in [19]. A complete system of those invariants of the second-rank tensor $\mathbf{T}$, mutually orthogonal vectors $\mathbf{p}$ and $\mathbf{q}$ which have the same power in the components of both vectors in $n$-dimensional space consist of $2 n$ invariants:

$$
I_{1}, \quad I_{2}, \quad \ldots, \quad I_{n}, \quad \mathbf{q} \cdot \mathbf{T} \cdot \mathbf{p}, \quad \mathbf{q} \cdot \mathbf{T}^{2} \cdot \mathbf{p}, \quad \ldots, \quad \mathbf{q} \cdot \mathbf{T}^{n-1} \cdot \mathbf{p} .
$$

Here $I_{k}$ is the absolute invariant of $\mathbf{T}$ defined by

$$
I_{k}=T_{\cdot\left[a_{1}\right.}^{a_{1} \cdot} T_{\cdot a_{2}}^{a_{2} \cdot} \cdots T_{\left.\cdot a_{k}\right]}^{a_{k}},
$$

where the alternation denotes by the square brackets around those indices to which it apply. The alterination in (25) is the operation prior to the contractions.

In case of $3 \mathrm{D}$-space the complete system of invariant (24) is reduced to

$$
I_{1}, \quad I_{2}, \quad I_{3}, \quad \mathbf{q} \cdot \mathbf{T} \cdot \mathbf{p}, \quad \mathbf{q} \cdot \mathbf{T}^{2} \cdot \mathbf{p} .
$$

The complete system of joint algebraic relative invariants (24) can be obtained by the well-known Cayley-Hamilton theorem $[44,45]$. The theorem can be easily proved for relative tensors. Actually, the Cayley-Hamilton theorem for an absolute second-rank (in general, asymmetric) tensor $\mathbf{T}$ in $n$-dimensional space [19] can be formulated by equation

$$
\mathbf{T}^{n}-I_{1} \mathbf{T}^{n-1}+I_{2} \mathbf{T}^{n-2}-\cdots+(-1)^{n} I_{n} \mathbf{I}=\mathbf{0},
$$

where $\mathbf{I}$ is the unit tensor. 
The relative tensor $\mathbf{T}$ can be transformed to an absolute one according to

$$
\mathbf{T}=e^{-w} \stackrel{[w]}{\mathbf{T}}
$$

For the invariants (25) of tensor $\mathbf{T}$ and relative invariants $\stackrel{[k w]}{I_{k}}$ of tensor $\stackrel{[w]}{\mathbf{T}}$ defined similarly to (25) and in view of (28) one can obtain

$$
I_{k}=e^{-k w} I_{k}^{[k w]} .
$$

After substituting representation of tensor $\mathbf{T}(28)$ and its invariants $I_{k}$ (29) in equation (27) we obtain

$$
e^{-n w}\left(\stackrel{[w]}{\mathbf{T}^{n}}-\stackrel{[w][w]}{I_{1}} \mathbf{T}^{n-1}+\stackrel{[2 w][w]}{I_{2}} \mathbf{T}^{n-2}-\cdots+(-1)^{n}{ }^{[n w]} I_{n} \mathbf{I}\right)=\mathbf{0} .
$$

A product of multipliers (30) is zero if and only if one or more of the multipliers is zero, which proves the Cayley-Hamilton theorem for the relative tensors.

Thus, the invariants system (26) in case of a growing micropolar solid can $[-1]$

apply by replacing tensor $\mathbf{T}$ by $\boldsymbol{\sigma}$ and then $\boldsymbol{\mu}$ and vectors $\mathbf{p}$ and $\mathbf{q}$ by $\underset{k}{\boldsymbol{\tau}}(k=1$ or 2) and $\mathbf{n}$ respectively. The invariants of tensors $\sigma^{i j}$ and $\stackrel{[-1]}{\mu}{ }_{. k}^{i .}$ will not involved in considerations due to their independence on a geometry of propagating growing surface.

A complete system of joint algebraic rational relative invariants can be developed according to list of invariants (26) due to joint inner products of considered vectors. Thus, a rationally system of algebraic rational relative invariants of tensor $\sigma^{i j}$ and vectors $n_{k}$ and $\underset{k}{\tau_{i}}$ is shown in table 4. A system for tensor ${ }_{\mu_{. k}}^{i \text {. }}$ and vectors $n_{k}$ and $\tau_{k}$ is given in table 5 . Note that, a literary search is shown an lack of results devoted to a system of joint ivariants of two second-rank tensors and two vectors. In table 6 we propose the joint algebraic rational relative invariants containing simultaneously tensors $\sigma^{i j}$ and ${ }^{[-1]} \mu_{. k}^{i}$.

As we can see, the system of joint algebraic rational relative invariants presented in the tables $4-6$ is complete but is not irreducible one. The invariants in $4^{\text {th }}, 6^{\text {th }}$, and $8^{\text {th }}$ rows in the table $4,4^{\text {th }}, 6^{\text {th }}$, and $8^{\text {th }}$ rows in the table 5 and $2^{\text {nd }}$, $4^{\text {th }}, 6^{\text {th }}$, and $8^{\text {th }}$ rows in the table 6 are not independent and can be excluded from consideration in virtue of obvious rational syzygies. Moreover, the joint algebraic rational relative invariants of higher order involving cubics and biquadratics in stresses and couples corresponding to $5^{\text {th }}-8^{\text {th }}$ rows in the table $4,5^{\text {th }}-8^{\text {th }}$ rows in the table $5,3^{\text {rd }}-8^{\text {th }}$ rows in the table 6 should be excluded from considerations according to the Cayley-Hamilton theorem [19].

Thus, the irreducible complete system of joint algebraic rational relative invariants of the force stress tensor $\sigma^{i j}$, couple stress tensor ${ }^{[-1]_{. k}}$ and vectors $n_{k}$ 
Table 4

Joint absolute rational invariants simultaneously involving the force stress tensor

\begin{tabular}{c|c|c}
\hline Vector form & Weight & Coordinate form \\
\hline $\mathbf{t} \cdot \mathbf{n}=\mathbf{n} \cdot \boldsymbol{\sigma} \cdot \mathbf{n}$ & 0 & $t^{k} n_{k}=n_{i} \sigma^{i k} n_{k}$ \\
$\mathbf{t} \cdot \mathbf{n}=\mathbf{n} \cdot \boldsymbol{\sigma}^{2} \cdot \mathbf{n}$ & 0 & $t_{2} n^{s}=n_{j} \sigma^{j i} \sigma_{i s} n^{s}$ \\
$\mathbf{t} \cdot \mathbf{t}$ & 0 & $g_{i j} t^{j} t^{i}$ \\
$\mathbf{t}_{\perp} \cdot \mathbf{t}_{\perp}$ & 0 & $g_{i j} t^{j} t^{i}-\left(t^{i} n_{i}\right)\left(t^{k} n_{k}\right)$ \\
$\mathbf{t} \cdot \mathbf{t}_{2}$ & 0 & $t_{2}^{i} t_{i}$ \\
$\mathbf{t}_{\perp} \cdot \mathbf{t}_{\perp}$ & 0 & $t_{2}^{i} t_{i}-\left(t^{i} n_{i}\right)\left({ }_{2} n^{k}\right)$ \\
${ }_{2}^{\mathbf{t}} \cdot{ }_{2}$ & 0 & $g_{2}^{i j} t_{i} t_{j}$ \\
$\mathbf{t}_{\perp} \cdot \mathbf{t}_{\perp}$ & 0 & $g^{i j} t_{i} t_{j}-\left({ }_{2} n^{i}\right)\left(t_{k} n^{k}\right)$ \\
\hline
\end{tabular}

Table 5

Joint relative rational invariants involving the couple stress tensor

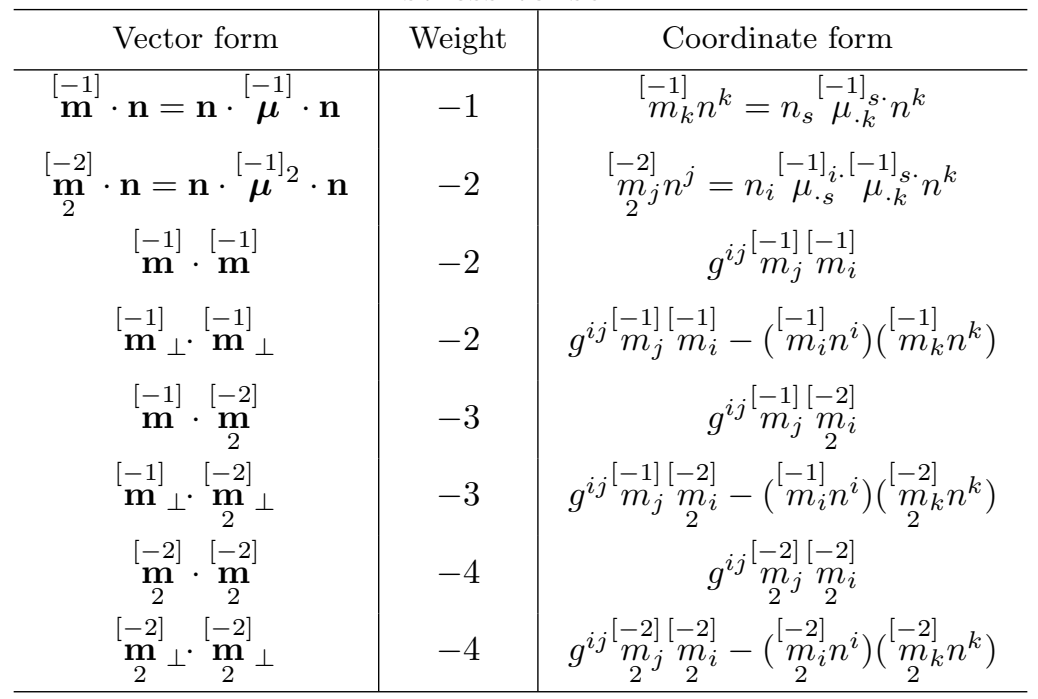

and $\tau_{k}$ can be and given by $1^{\text {st }}-3^{\text {rd }}$ rows in the table $4,1^{\text {st }}-3^{\text {rd }}$ rows in the table 5 , $1^{\text {st }}$ and $2^{\text {nd }}$ rows in the table 6 . Such system will be insensitive to a rotation of the local coordinate frame $\left(n_{i}, \tau_{i}, \tau_{2}\right)$ around the unit normal vector $n_{i}$ to the propagating growing surface $\Sigma$.

\section{Algebraic invariants sensitive to mirror reflections}

As shown in Sec.3, the hemitropic constitutive pseudoscalars are sensitive to the mirror reflections and 3D-space inversions. Thus, we should pay attention to invariants sensitive to mentioned transformations. Consider a propagating growing 


\section{Table 6}

Joint relative rational invariants involving the force and couple stress tensor

\begin{tabular}{|c|c|c|}
\hline Vector form & Weight & Coordinate form \\
\hline $\mathbf{t} \cdot \stackrel{[-1]}{\mathbf{m}}$ & -1 & $t^{i}{ }^{[-1]}{ }_{i}=n_{i} \sigma^{i k}{ }^{[-1]} \mu_{\cdot k} \cdot n_{s}$ \\
\hline $\mathbf{t}_{\perp} \cdot \stackrel{[-1]}{\mathbf{m}} \perp_{\perp}$ & -1 & $t^{i} \stackrel{[-1]}{m}_{i}-\left(g^{i j} \stackrel{[-1]}{m}_{j} n_{i}\right)\left(t^{k} n_{k}\right)$ \\
\hline $\mathbf{t} \cdot \underset{2}{[-2]}$ & -2 & $t^{i} \underset{2}{m_{i}^{[-2]}}$ \\
\hline $\mathbf{t}_{\perp} \cdot \stackrel{[-2]}{\mathbf{m}}_{2}$ & -2 & $t^{i}{ }_{2}^{[-2]}{ }_{i}-\left(t^{i} n_{i}\right)\left(g^{i j}{ }_{2}^{[-2]} n_{i}\right)$ \\
\hline$\stackrel{[-1]}{\mathbf{m}} \cdot \mathbf{t}$ & -1 & $g^{i j} \stackrel{-1]}{m}_{j} t_{i}$ \\
\hline$\stackrel{[-1]}{\mathbf{m}}{ }_{\perp} \cdot \mathbf{t}_{\perp}$ & -1 & $g^{i j}{ }^{[-1]} m_{j} t_{i}-\left({ }^{[-1]} m_{i} n^{i}\right)\left(t_{2} n^{k}\right)$ \\
\hline$\underset{2}{\mathbf{t}} \cdot \stackrel{[-2]}{\mathbf{m}}_{2}$ & -2 & $g^{i j} t_{i}{ }_{2}^{[-2]}{ }_{2}^{m_{j}}$ \\
\hline $\mathbf{t}_{2} \cdot \cdot \mathbf{m}_{2}^{[-2]}$ & -2 & $g^{i j}{ }_{2} t_{i}{ }_{2}^{[-2]} m_{j}-\left(t_{k} n^{k}\right)\left({ }_{2}^{[-2]} n_{j}^{j}\right)$ \\
\hline
\end{tabular}

surface located in 3D-space and introduce local coordinate frame consisted of mutually orthogonal vectors: a unit normal vector $n_{i}$, and the two unit vectors in a tangent plane $\tau_{i}, \tau_{2}$. In case of 3D-space transformation sensitive to an inversion, we need to descriminate those invariants shown in the tables 4-6 that have an odd weight. Thus, the system of joint algebraic rational relative invariants is defined by $1^{\text {st }}, 5^{\text {th }}$, and $6^{\text {th }}$ rows in the table 5 and $1^{\text {st }}, 2^{\text {th }}, 5^{\text {th }}$, and $6^{\text {th }}$ rows in the table 6 . The irreducible system of joint algebraic rational relative invariants sensitive to the mirror reflections and $3 \mathrm{D}$-space inversions consists of $1^{\text {st }}$ row in the table 5 and $1^{\text {st }}$ row in the table 6 .

\section{Conclusions}

(i) The formulation of the virtual work principle for the micropolar solids of a constant staff has been discussed. The weights of the fundamental relative tensors have been estimated and collected in table 1 .

(ii) The static equations in an arbitrary curvilinear coordinate system has been furnished. The weights of relative tensors of micropolar elasticity are verified and given in table 2 .

(iii) The elastic potential (treated as an absolute scalar) of the hemitropic micropolar continuum have been given and discussed. The weights of the micropolar hemitropic constitutive scalars have been discussed and then shown by table 3 . The rate form of static equations have been obtained.

(iv) The boundary conditions on the propagating growing surface have been furnished by transformation of the micropolar equilibrium equations.

(v) The joint algebraic rational relative invariants of force stress tensor, couple stress tensor and the unit normal vector to the propagating growing surface have been presented in tables 4-6. 
(vi) The system of joint algebraic rational relative invariants insensitive to a coordinate frame rotation around the unit normal vector to the propagating growing surface has been proposed and discussed.

(vii) Invariants sensitive to the mirror reflections and 3D-space inversions have been discriminated and discussed.

Competing interests. We declare that we have no competing interests.

Author's Responsibilities. We take full responsibility for submitting the final manuscript in print. We approved the final version of the manuscript.

Funding. This study was in part financially supported by the Ministry of Science and Higher Education of the Russian Federation (State Registration Number AAAA-A20120011690132-4) and by the Russian Foundation for Basic Research projects nos. 1801-00844, 19-51-60001, 20-01-00666.

Acknowledgments. The authors are grateful to the reviewers for careful reading of the paper and valuable improvements, suggestions and comments.

\section{References}

1. Berman B. 3-D printing: The new industrial revolution, Business Horizons, 2012, vol. 55, no. 2, pp. 155-162. https://doi.org/10.1016/j.bushor.2011.11.003.

2. Southwell R. V. An introduction to the theory of elasticity. For engineers and physicists, Oxford Engineering Science Series. London, Oxford Univ. Press, 1936.

3. Epstein M., Maugin G. A. Thermomechanics of volumetric growth in uniform bodies, Int. J. Plast., 2000, vol. 16, no.7-8, pp. 951-978. https://doi.org/10.1016/S0749-6419(99) 00081-9.

4. Maugin G. A. On inhomogeneity, growth, ageing and the dynamics of materials, J. Mech. Mater. Struct., 2009, vol. 4, no. 4, pp. 731-741. https://doi.org/10.2140/jomms.2009.4. 731.

5. Ciarletta P., Preziosi L., Maugin G. A. Mechanobiology of interfacial growth, J. Mech. Phys. Solids, 2013, vol.61, no. 3, pp. 852-872. https://doi.org/10.1016/j.jmps.2012.10.011.

6. Ciarletta P., Ambrosi D., Maugin G. A., Preziosi L. Mechano-transduction in tumour growth modelling Physical constraints of morphogenesis and evolution, Eur. Phys. J. E, 2013, vol. 36, 23. https://doi.org/10.1140/epje/i2013-13023-2.

7. Ciarletta P., Ambrosi D., Maugin G. A. Configurational forces for growth and shape regulations in morphogenesis, Bull. Pol. Acad. Sci., Tech. Sci., 2012, vol. 60, no. 2, pp. 253-257. https://doi.org/10.2478/v10175-012-0034-5.

8. Porubov A. V., Maugin G. A. Application of non-linear strain waves to the study of the growth of long bones, Int. J. Non-Linear Mech., 2011, vol.46, no. 2, pp. 387-394. https:// doi.org/10.1016/j.ijnonlinmec.2010.10.004.

9. Maugin G. A. From the propagation of phase-transition fronts to the evolution of the growth plate in long bones, Proc. Est. Acad. Sci., 2010, vol. 59, no. 2, pp. 72-78. https://doi.org/ 10.3176/proc. 2010.2.03.

10. Ciarletta P., Preziosi L., Maugin G. A. Thermo-mechanics of growth and mass transfer: morphogenesis of seashells, Computer Methods in Biomechanics and Biomedical Engineering, 2012, vol. 15, no. Suppl. 1, pp. 110-112. https://doi.org/10.1080/10255842.2012.713679.

11. Ciarletta P., Maugin G. A. Elements of a finite strain-gradient thermomechanical theory for material growth and remodeling, Int. J. Non-Linear Mech., 2011, vol.46, no. 10, pp. 1341-1346. https://doi.org/10.1016/j.ijnonlinmec.2011.07.004.

12. Goriely A. The Mathematics and Mechanics of Biological Growth, Interdisciplinary Applied Mathematics, vol. 45. New York, Springer, 2017, xxii+646 pp. https://doi.org/10.1007/ 978-0-387-87710-5. 
13. Veblen O., Thomas T. Y. Extensions of Relative Tensors, Trans. Amer. Math. Soc., 1924, vol. 26, no. 3, pp. 373-377. https://doi.org/10.1090/S0002-9947-1924-1501284-6.

14. Veblen O. Invariants of Quadratic Differential Forms, Cambridge Tracts in Mathematics and Mathematical Physics, vol.24. Cambridge, Cambridge University Press, 1927, viii +102 pp.

15. Levi-Cività T. The Absolute Differential Calculus (Calculus of Tensors). London, Glasgow, Blackie \& Son, 1927, xvi+450 pp.

16. Hawking S. W., Israel W. General Relativity. An Einstein Centenary Survey. Cambridge, Cambridge University Press, 1979, xviii+919 pp.

17. Schouten J. A. Tensor Analysis for Physicist. New York, Oxford University Press, 1951, 276 pp.

18. Sokolnikoff I. S. Tensor Analysis: Theory and Applications to Geometry and Mechanics of Continua, Applied Mathematics Series. New York, John Wiley \& Sons, 1964, xii +361 pp.

19. Gurevich G. B. Foundations of the Theory of Algebraic Invariants. Gröningen, P. Noordhoff, 1964, viii +429 pp.

20. Synge J. L., Schild A. Tensor Calculus, vol. 5. New York, Courier Corporation, 1978, 334 pp.

21. Truesdell C., Toupin R. The Classical Field Theories, In: Principles of Classical Mechanics and Field Theory. Encyclopedia of Physics, Encyclopedia of Physics, vol. 2/3/1; eds. S. Flügge. Berlin, Heidelberg, Springer, 1960, pp. 226-902. https://doi.org/10.1007/ 978-3-642-45943-6_2.

22. Das A. J. Tensors: The mathematics of relativity theory and continuum mechanics. New York, Springer, 2007, xii+290 pp. https://doi .org/10.1007/978-0-387-69469-6.

23. Rashba E. I. Stresses computation in massive construction under their own weight taking into account the construction sequence, Proc. Inst. Struct. Mech. Acad. Sci. Ukrainian SSR, 1953, no. 18, pp. 23-27 (In Russian).

24. Kharlab V. D. Linear creep theory of the build-up body. Mechanics of rod systems and solid mediums, In: The Proceedings of the Leningrad Civil Engineering Institute, vol. 49. Leningrad, Leningrad Civil Engineering Institute, 1966, pp. 93-119 (In Russian).

25. Arutyunyan N. Kh., Naumov V. E., Radayev Yu. N. Dynamic expansion of an elastic layer. Part 1. Motion of a flow of precipitated ppapers at a variable rate, Izv. Akad. Nauk. Mekh. Tverd. Tela, 1992, no. 5, pp. 6-24 (In Russian).

26. Arutyunyan N. Kh., Naumov V. E., Radayev Yu. N. Dynamical expansion of an elastic layer. Part 2. The case of drop of accreted ppapers at a constant rate, Izv. Akad. Nauk. Mekh. Tverd. Tela, 1992, no. 6, pp. 99-112 (In Russian).

27. Naumov V. E., Radayev Yu. N. Thermomechanical model of an growing solids: Variational formulation, Preprint no. 527. Moscow, IPMech RAS, 1993, 39 pp. (In Russian)

28. Dmitrieva A. M., Naumov V. E., Radayev Yu. N. Growth of thermoelastic spherical layer: Application of the variational approach, Preprint no. 528. Moscow, IPMech RAS, 1993, 64 pp. (In Russian)

29. Kovalev V. A., Radayev Yu. N. On a form of the first variation of the action integral over a varied domain, Izv. Saratov Univ. (N.S.), Ser. Math. Mech. Inform., 2014, vol. 14, no. 2, pp. 199-209 (In Russian). https://doi.org/10.18500/1816-9791-2014-14-2-199-209.

30. Arutyunyan N. Kh., Naumov V. E. The boundary value problem of the theory of viscoelastic plasticity of a growing body subject to aging, J. Appl. Math. Mech., 1984, vol. 48, no. 1, pp. 1-10. https://doi.org/10.1016/0021-8928(84)90099-6.

31. Trincher V. K. On the formulation of the problem of stresses calculation in the gravitational state of a growing solid, Izv. Akad. Nauk SSSR. Mekh. Tverd. Tela, 1984, no. 2, pp. 119-124 (In Russian).

32. Bykovtsev G. I. Izbrannye problemnye voprosy mekhaniki deformiruemykh sred [Selected Problems from Solid Mechanics. Collection of papers]. Vladivostok, Dal'nauka, 2002, 566 pp. (In Russian)

33. Radayev Yu. N. The Lagrange multipliers method in covariant formulations of micropolar continuum mechanics theories, Vestn. Samar. Gos. Tekhn. Univ., Ser. Fiz.-Mat. Nauki 
[J. Samara State Tech. Univ., Ser. Phys. Math. Sci.], 2018, vol. 22, no. 3, pp. 504-517 (In Russian). https://doi.org/10.14498/vsgtu1635.

34. Courant R., Gilbert D. Metody matematicheskoi fiziki [Methods of Mathematical Physics]. Moscow, Leningrad, Gostekhteoretizdat, 1933, 528 pp. (In Russian)

35. Gelfand I. M., Fomin S. V. Variatsionnoe ischislenie [Calculus of Variations]. Moscow, Fizmatlit, 1961, 228 pp. (In Russian)

36. Gunter N. M. Kurs variatsionnogo ischisleniia [A Course of the Calculus of Variations]. Moscow, Leningrad, Gostekhteoretizdat, 1941, 308 pp. (In Russian)

37. Kovalev V. A., Radayev Yu. N. On wave solutions of dynamic equations of hemitropic micropolar thermoelasticity, Izv. Saratov Univ. (N.S.), Ser. Math. Mech. Inform., 2019, vol.19, no.4, pp. 454-463 (In Russian). https://doi.org/10.18500/ 1816-9791-2019-19-4-454-463.

38. Radayev Yu. N., Kovalev V. A. On plane thermoelastic waves in hemitropic micropolar continua, Vestn. Samar. Gos. Tekhn. Univ., Ser. Fiz.-Mat. Nauki [J. Samara State Tech. Univ., Ser. Phys. Math. Sci.], 2019, vol.23, no.3, pp. 464-474. https://doi.org/ 10.14498/vsgtu1689.

39. Rosenfeld B. A. Mnogomernye prostranstva [Multidimensional Spaces]. Moscow, Nauka, 1966, 648 pp. (In Russian)

40. Rosenfeld B. A. A History of Non-Euclidean Geometry: Evolution of the Concept of a Geometric Space, Studies in the History of Mathematics and Physical Sciences, vol. 12. New York, Springer, 1988, ix+471 pp. https://doi .org/10.1007/978-1-4419-8680-1.

41. Murashkin E. V., Radayev Yu. N. On a differential constraint in asymmetric theories of the mechanics of growing solids, Mech. Solids, 2019, vol. 54, no. 8, pp. 1157-1164. https://doi. org/10.3103/S0025654419080053.

42. Murashkin E. V., Radayev Yu. N. On a differential constraint in the continuum theory of growing solids, Vestn. Samar. Gos. Tekhn. Univ., Ser. Fiz.-Mat. Nauki [J. Samara State Tech. Univ., Ser. Phys. Math. Sci.], 2019, vol.23, no.4, pp. 646-656. https://doi.org/ 10.14498/vsgtu1696.

43. Murashkin E. V., Radayev Yu. N. On a Class of Constitutive Equations on Propagating Growing Surface, Bulletin of the Yakovlev Chuvash State Pedagogical University. Series: Mechanics of Limit State, 2019, no.3(41), pp. 11-29 (In Russian). https://doi.org/10. 26293/chgpu. 2019.40.2.012.

44. Hamilton W. R. Lectures on Quaternions. Cambridge, Cambridge University Press, 1866, lx+762 pp. https://doi.org/10.1017/CB09780511707162.

45. Cayley A. A memoir on the theory of matrices, Philos. Trans. R. Soc. Lond., 1858, no. 148, pp. 17-37. https://doi.org/10.1098/rstl.1858.0002. 
Вестн. Сам. гос. техн. ун-та. Сер. Физ.-мат. науки. 2020. Т. 24, № 3. С. 424-444 ISSN: 2310-7081 (online), 1991-8615 (print)

УДК 539.319

\title{
О микрополярной 3D-теории растущих тел
}

\author{
(C) Е. В. Мурашкин, Ю. Н. Радаев
}

Институт проблем механики им. А. Ю. Ишлинского РАН, Россия, 119526, Москва, просп. Вернадского, 101, корп. 1.

\section{Аннотация}

Обсуждается принцип вывода граничных условий в краевых задачах механики растущих микрополярных тел. Приводится вывод уравнений динамики микрополярного континуума в терминах относительных тензоров для тел постоянного состава. Указана определяющая квадратичная форма упругого потенцила (абсолютного скаляра) для линейного гемитропного микрополярного тела. Выведены определяющие соотношения для симметричных и антисимметричных частей тензоров силовых и моментных напряжений. Получены конечные формы уравнений динамики гемитропного микрополярного континуума в терминах скоростей перемещений и микровращений. Полученные динамические уравнения для тел постоянного состава остаются справедливыми и в теориях растущих тел. Предложена процедура преобразования уравнений равновесия для получения граничных условий на поверхности наращивания в терминах относительных тензоров в форме дифференциальных ограничений. Полученные условия справедливы для весьма широкого круга материалов и метаматериалов. При выводе определяющих соотношений на поверхности наращивания активно используется аппарат алгебры рациональных относительных инвариантов. Получены полные системы совместных относительных инвариантов для тензоров силовых, моментных напряжений и единичного вектора нормали, в том числе системы инвариантов, не выдерживающие зеркальных отражений.

Ключевые слова: микрополярный гемитропный континуум, микроповорот, псевдоскаляр, относительный тензор, 3D-печать, поверхностный рост, напряжение, определяющее уравнение, рациональный относительный инвариант, дифференциальное ограничение, полная система.

Получение: 15 июня 2020 г. / Исправление: 17 августа 2020 г. / Принятие: 14 сентября 2020 г. / Публикация онлайн: 30 сентября 2020 г.

\section{Научная статья}

ə (9) Ко Контент публикуется на условиях лицензии Creative Commons Attribution 4.0 International (https://creativecommons.org/licenses/by/4.0/deed.ru)

\section{Образец для цитирования}

M u rashkin E. V., R a d a y ev Yu. N. On a micropolar theory of growing solids, Vestn. Samar. Gos. Tekhn. Univ., Ser. Fiz.-Mat. Nauki [J. Samara State Tech. Univ., Ser. Phys. Math. Sci.], 2020, vol. 24, no. 3, pp. 424-444. https://doi.org/10.14498/vsgtu1792.

\section{Сведения об авторах}

Евгений Валерьевич Мурашкин (10) https://orcid.org/0000-0002-3267-4742

к.ф.-м.н.; старший научный сотрудник; лаб. моделирования в механике деформируемого твердого тела; e-mail: evmurashkin@google.com

Юрий Николаевич Радаев (1) https://orcid.org/0000-0002-0866-2151

доктор физико-математических наук, профессор; ведущий научный сотрудник; лаб. моделирования в механике деформируемого твердого тела; e-mail:radayev@ipmnet.ru, y.radayev@gmail.com 
Конкурирующие интересы. Заявляем, что в отношении авторства и публикации этой статьи конфликта интересов не имеем.

Авторский вклад и ответственность. Все авторы принимали участие в разработке концепции статьи и в написании рукописи. Авторы несут полную ответственность за предоставление окончательной рукописи в печать. Окончательная версия рукописи была одобрена всеми авторами.

Финансирование. Работа выполнена в рамках государственного задания (№ госрегистрации АААА-А20-120011690132-4) и при поддержке Российского фонда фундаментальных исследований проекты (№№ 18-51-00844, 19-51-60001, 20-01-00666).

Благодарности. Авторы благодарят рецензента за внимательное прочтение статьи, ценные предложения и комментарии.

Математический институт им. В.А. Стеклова Российской академии наук приступает к работе в рамках Государственного контракта № 13.597.11.0043 по теме «Создание электронного архива выпусков научных журналов по тематическому направлению «Математика, физика, информационные технологии». Архив будет размещен на Общероссийском портале Math-Net.Ru.

Предполагается пополнить коллекцию Math-Net.Ru архивами ряда ведущих журналов по математике, физике и информационным технологиям, а также материалами научных мероприятий.

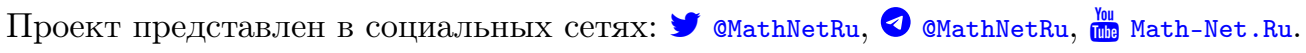

